\title{
Methicillin resistance and clonal diversity of Staphylococcus aureus isolated from nasal samples of healthy horses in Iran
}

\author{
Habib Dastmalchi Saei ${ }^{1}$ (D) Elahe Safari ${ }^{1}$ \\ Received: 24 January 2019 / Accepted: 22 May 2019 / Published online: 5 June 2019 \\ (C) Università degli studi di Milano 2019
}

\begin{abstract}
Purpose The aims of the current study were to investigate the frequency and genetic diversity of Staphylococcus aureus from healthy horses, including both methicillin-resistant (MRSA) and -susceptible S. aureus (MSSA).

Methods Three hundred-one nasal swabs were collected from healthy horses in three provinces, Iran. Sixty-one of the 301 tested samples contained S. aureus (20.3\%), among which five were MRSA. Isolates were typed by spa PCR-RFLP and agr typing, followed by sequence-based spa typing and MLST on representative strains from each restriction pattern and SCCmec typing for MRSA strains. The presence of Panton-Valentine Leukocidin (PVL) encoding genes was also tested using PCR.

Results Eight distinct RFLP patterns (designated as N1-N8) were observed, with N2 (23/61; 37.7\%) and N4 (18/61; 29.5\%) the most common. On sequencing, N1-N8 patterns were found to be of clonal types ST15-t084, ST2151-t2484, ST291-t937, ST1t127, and ST1-t1383, ST700-t11926, ST133-t1166, and ST1278-t12595, respectively. No PVL-positive S. aureus were detected. Five MRSA were identified as ST2151-t2484-SCCmecIVa (2 isolates), ST15-t084-SCCmecIVa, ST1-t1383-SCCmecIVa, and t12595-SCCmecIVa (one isolate each). Majority of $S$. aureus isolates were ascribed to agr types III $(n=30 ; 49.2 \%)$ and IV $(n=$ $28 ; 45.9 \%)$, followed by types II $(n=2,3.3 \%)$ and I $(n=1,1.6 \%)$. The carriage of $S$. aureus was found to be associated with geographic locations.

Conclusions This study for the first time describes the circulation of diverse clones of MSSA and MRSA among the Iranian horse population. This may pose a public health risk, which supports the need for their epidemiological monitoring.
\end{abstract}

Keywords Horse $\cdot$ Methicillin resistant $\cdot$ Nasal $\cdot$ Clonal diversity $\cdot S$. aureus

\section{Introduction}

Staphylococcus aureus is an important pathogen that can asymptomatically colonize the nares of diverse animals. Of particular concern is methicillin-resistant $S$. aureus (MRSA), which has become a major threat due to an increasing incidence in companion animals, including horses and animals raised for human consumption (Weese and van Duijkeren 2010). The emergence of methicillin-resistant strains of $S$. aureus is due to the acquisition of a staphylococcal cassette chromosome mec (SCCmec) element harboring the mecA or mecC gene (Liu

Habib Dastmalchi Saei

HDSaei561@gmail.com; h.dastmalchi@urmia.ac.ir

1 Department of Microbiology, Faculty of Veterinary Medicine, Urmia University, PO Box 1177, Urmia, Iran et al. 2016). The populations of MRSA are classified on the basis of their origin as hospital associated (HAMRSA), community associated (CA-MRSA), and livestock associated (LA-MRSA) (Gopal and Divya 2017). Studies demonstrated that nasal mucosa of farm animals represents a potential reservoir of MRSA that, in turn, may serve as an important source for environmental contamination (Peterson et al. 2012). Colonization is also a substantial risk factor for autoinfection and colonized horses pose a risk to other animals and humans (Cohn and Middleton 2010; Axon et al. 2011; Agabou et al. 2017). In this regard, MRSA skin infections as a result of horse to human transmission have been reported in several studies (Weese et al. 2005, 2006).

Subtyping is a key point for epidemiologic investigation and subsequent design of public health control strategies. Many different molecular techniques have been extensively exploited for classifying $S$. aureus strains of which Staphylococcal Protein A (spa) typing and multilocus 
sequence typing (MLST) are considered to be wellestablished discriminatory methods (Enright et al. 2000; Koreen et al. 2004). These two methods can be used in conjunction with software-based clustering algorithms that group related isolates into clonal complexes (CCs). The algorithms used with spa typing and MLST to cluster spa types into spa CCs and MLST sequence types (STs) into MLST CCs are Based Upon Repeat Pattern (BURP) and Based $\underline{\text { Uppon }}$ Related Sequence Types (BURSTs), respectively (O'Hara et al. 2016). Other techniques such as polymerase chain reaction-restriction fragment length polymorphism (PCRRFLP) of the spa gene (Wichelhaus et al. 2001) and accessory gene regulator (agr) typing (Gilot et al. 2002) could also be used for epidemiological investigation of $S$. aureus strains. For MRSA, SCCmec typing is another indispensable method of typing which classifies SCCmec elements based on their structural organization and genetic content. To date, a total of 13 SCCmec types (I-XIII) have been reported, with SCCmec types I, II, or III predominant in HA-MRSA strains, whereas types IV or V were the most common in CA-MRSA strains (Lakhundi and Zhang 2018). In addition, Panton-Valentine Leukocidin (PVL) is a gene encoding a potent pore-forming cytotoxin that is strongly associated with CA-MRSA strains (Asghar 2014).

Although some studies have indicated that horses are colonized or infected by MRSA strains commonly related to CC8 (Weese and van Duijkeren 2010; Carfora et al. 2016), the genetic background of MRSA strains isolated from equids varies in different regions around the world (Carfora et al. 2016). In Iran, there is a long history in horse domestication and breeding and Iranian horse breeds can be classified into four main groups according to their origins and habitats as follows: Caspian breed in North alluvial plains, Turkmen breed in northeast fields, Kurd breed in west highlands, and Persian Arab breed (Asil) in central plateau (Moridi et al. 2013). However, the epidemiology of $S$. aureus in horses has not been well studied and it is also unclear how widely dispersed MRSA is in the horse population. Therefore, the aim of the present study was to investigate, for the first time, the frequency and genetic diversity of $S$. aureus isolates (either MSSA or MRSA) from healthy horses of various breeds housed in different geographic locations of Iran.

\section{Materials and methods}

\section{Sample collection and bacterial identification}

A total of 301 healthy horses were sampled from different Iranian provinces including Yazd (136 horses in five farms $[\mathrm{A}-\mathrm{E}]$ ) which is part of the Central Iranian Plateau where Iran's deserts are mainly located in, West Azerbaijan (63 horses in two farms [F and G] as well as a local rodeo) and East Azerbaijan (102 horses in four farm $[\mathrm{H}-\mathrm{K}]$ ) which are located in the northwest of the country. Horses were excluded if they had signs of upper respiratory tract infection or had antimicrobial administration in the preceding 14 days. Of the 301 horses swabbed, 195 were Iranian indigenous breeds including Persian Arab (Asil) $(n=85)$, Turkmen $(n=47)$, and Kurd $(n=63)$, the remaining horses were Thoroughbred $(n=$ $51)$ and crossbred $(n=55)$ with a median age of 8 years (range 4 to 13 years old). Horses from West Azerbaijan province were raised near the northwest borders of the country on wide open spaces and used for work, while horses from Yazd and East Azerbaijan provinces housed in individual stalls in a stable and used for riding. On the other hand, farm in Yazd province characterized by confinement and intensive management and little direct contact between farms as well. Farms in the East and West Azerbaijan provinces had semi-intensive management system. Samples were obtained by inserting the same moistened sterile swab into both nostrils, and then rolling it against the nasal wall while removing. Collection of samples was approved by the Urmia University Animal Ethics Committee (UUAEC, authorization no. 1241). The swabs were enriched for $24 \mathrm{~h}$ at $37^{\circ} \mathrm{C}$ in nutrient broth containing $6 \% \mathrm{NaCl}$ and inoculated onto Mannitol Salt Agar (MSA) selective for $S$. aureus (Maddox et al. 2011). Incubation was carried out for $24 \mathrm{~h}$ at $37{ }^{\circ} \mathrm{C}$. On evaluation of the growth on the selective medium, $S$. aureus-suspicious colonies were purified on blood agar plates containing 5\% sheep blood for $24 \mathrm{~h}$ at $37{ }^{\circ} \mathrm{C}$. Isolates were then subjected to conventional methods (Gram stain, catalase test, tube coagulase, DNase, and fermentation of mannitol) as well as PCR amplification of $S$. aureus specific-nuc gene (Brakstad et al. 1992) and frozen in brain heart infusion broth (BHI, Merck, Germany) with $15 \%$ glycerol at $-20{ }^{\circ} \mathrm{C}$.

\section{Detection of methicillin resistance}

All S. aureus isolates were evaluated for methicillin resistance by disk diffusion method and endpoint PCR to detect the $m e c A$ gene, a determinant of methicillin resistance. Disk diffusion was performed on Mueller-Hinton agar plates (Oxoid) using 30- $\mu$ g cefoxitin disk (Oxoid) (CLSI 2009). Isolates showing inhibition zone diameter $\leq 21 \mathrm{~mm}$ were classified as resistant. For the detection of $m e c A$, we used the primer pair 5'-AAA ATC GAT GGT AAA GGT TGG C-3' and 5'-AGT TCT GCA GTA CCG GAT TTG C-3' as described previously (Murakami et al. 1991). A methicillinsusceptible S. aureus strain (ATCC 29213) and a MRSA strain (ATCC 33591) were used as control organisms for the disk diffusion and PCR assays. 
Determination of accessory gene regulator (agr) type

The agr typing was carried out for determination of the $a g r$ groups (I-IV) using the agr-group-specific multiplex PCR by primers as described by Gilot et al. (2002), which involves a forward primer (pan-agr) common to all agr groups (Pan: $5^{\prime}$ ATG CAC ATG GTG CAC ATG C-3') and four primers, each one specific to each agr group (agr1: 5'-GTC ACA AGT ACT ATA AGC TGC GAT-3'; agr2: 5'-TAT TAC TAA TTG AAA AGT GGC CAT AGC-3'; agr3: 5'-GTA ATG TAA TAG CTT GTA TAA TAA TAC CCA G-3'; and agr4: 5'-CGA TAA TGC CGT AAT ACC CG-3'). The PCR products of 441, 575, 323, and $659 \mathrm{bp}$ represent the agr types I, II, III, and IV, respectively. S. aureus agr reference strains RN6390 (agr group 1), RN6923 (agr group 2), RN8462 (agr group 3), and A880740 (agr group 4) were used as controls.

\section{RFLP analysis of the PCR-amplified spa gene}

The primers SPA1 (5'-ATC TGG TGG CGT AAC ACC TG$3^{\prime}$ ) and SPA2 (5'-CGC TGC ACC TAA CGC TAA TG-3') described by Wichelhaus et al. (2001) were used to amplify the polymorphic $\mathrm{X}$ region of spa gene. Amplification was carried out in Corbett thermocycler (Model CP2-003, Australia) through the following temperature program: $4 \mathrm{~min}$ of initial denaturation at $94{ }^{\circ} \mathrm{C} ; 35$ cycles consisting of $1 \mathrm{~min}$ at $94{ }^{\circ} \mathrm{C}, 1 \mathrm{~min}$ at $56{ }^{\circ} \mathrm{C}$, and $3 \mathrm{~min}$ at $72{ }^{\circ} \mathrm{C}$; and a final extension for $5 \mathrm{~min}$ at $72{ }^{\circ} \mathrm{C}$. The presence of a PCR product was determined by electrophoresis in a $1.2 \%(w / v)$ agarose gels. Then, approximately $7-10 \mu \mathrm{L}$ of PCR product $(500 \mathrm{ng})$ was digested with $6 \mathrm{U}$ of restriction endonuclease HaeII at $37^{\circ} \mathrm{C}$ for $3 \mathrm{~h}$. Ten microliters of digested PCR products was analyzed by electrophoresis in $1.2 \%$ agarose gel containing $0.5 \mu \mathrm{g} / \mathrm{mL}$ ethidium bromide at $100 \mathrm{~V}$ for $1 \mathrm{~h}$ and $20 \mathrm{~min}$ and visualized under UV light.

\section{spa typing, BURP, and phylogenetic analysis}

For this, spa gene fragment of the representative isolates from each RFLP patterns (N1-N8) was amplified using primer set 2 (spa-1113f: 5'-TAA AGA CGA TCC TTC GGT GAG C-3' and spa-1514r: 5'-CAG CAG TAG TGC CGT TTG CTT-3') under the following reaction conditions: (i) $5 \mathrm{~min}$ at $94^{\circ} \mathrm{C}$; (ii) 35 cycles of $45 \mathrm{~s}$ at $94{ }^{\circ} \mathrm{C}, 45 \mathrm{~s}$ at $60^{\circ} \mathrm{C}$, and $90 \mathrm{~s}$ at $72^{\circ} \mathrm{C}$; and (iii) 10 min at $72{ }^{\circ} \mathrm{C}$ (Johler et al. 2011). The resultant PCR products were separated in $1.5 \%$ agarose gel and the gel was photographed using ultraviolet transillumination. After gel purification (GeneJET Gel Extraction and DNA Cleanup Micro Kit; Thermo Scientific, Germany), the PCR products were sent for sequencing (SinaClon, Iran). The sequences were assigned to spa types using the Ridom SpaServer database (http://www.spaserver.ridom.de/) (Harmsen et al. 2003) via DNAGear (AL-Tam et al. 2012). The BURP (Based Upon
Repeat Patterns) algorithm analysis of the spa types was performed in the Ridom StaphType software (Ridom GmbH, Germany) to cluster related spa types. Analysis was done with two default parameters for cluster designation: (1) "exclude $s p a$ types that are shorter than 5 repeats" and (2) "cluster spa types into the same group if cost distances are less than or equal to 4 repeats". A cluster consisting of two or more related spa types was regarded as a clonal complex. A singleton was defined as a spa type that was not grouped into a clonal complex (Mellmann et al. 2007). The spa sequences obtained in this study were aligned using ClustalW, and the phylogenetic analysis was performed employing the maximum likelihood (ML) method using MEGA 6.06 program. The confidence level of branching in the phylogenetic tree was evaluated with the bootstrap test based on 1000 resamplings.

\section{Multilocus sequence typing and eBURST analysis}

MLST was performed on representative $S$. aureus isolates from individual spa types as well as on MRSA isolates with the primers targeting seven distinct loci as described previously (Enright et al. 2000). After sequencing of the purified PCR products, allelic profile and sequence type (ST) of each isolate were assigned using the MLST website (http://www.mlst.net). The relatedness of identified STs against already deposited worldwide data was analyzed with the eBURST algorithm (version 3.0). Isolates that shared six of seven MLST loci belonged to the same $\mathrm{CC}$.

\section{SCCmec typing and type IV SCCmec subtyping}

Staphylococcal cassette chromosome mec (SCCmec) typing of MRSA isolates was performed via multiplex PCR using the primers described previously (Boye et al. 2007). To distinguish between the different SCCmec IV subtypes, a further multiplex PCR was performed as previously described (Milheirico et al. 2007).

\section{Detection of PVL genes}

The detection of genes encoding the Panton-Valentine leukocidin (PVL, lukS-lukF-PV) was also carried out by PCR using the primers luk-PV-1 (5'-ATC ATT AGG TAA AAT GTC TGG ACA TGA TCC A-3') and luk-PV-2 (5'GCA TCA AST GTA TTG GAT AGC AAA AGC-3') which amplify a 433 base pair fragment (Lina et al. 1999).

\section{Statistical analysis}

The association between $S$. aureus nasal carriage and geographical area was determined using Chi-Squared test. Statistical analysis was performed using SPSS Software version 22 (IBM SPSS Statistics for Windows, Armonk, NY, 
USA: IBM Corp.). A $P$ value $<0.05$ was considered statistically significant.

\section{Results}

In all, 61 S. aureus (20.3\%) strains were obtained from 301 horse nasal swab samples, of which $5(8.2 \%)$ were found to be methicillin resistant (Table 1). As shown, $S$. aureus was isolated from 25 of $102(24.5 \%)$ horses from East Azerbaijan, 26 of $63(41.3 \%)$ horses from West Azerbaijan, and 10 of 136 (7.4\%) horses from Yazd province. The prevalence of S. aureus colonization by breed was as follows: $29.1 \%$ (16/ $55)$ in crossbred, $19.1 \%(9 / 47)$ in Turkmen, $41.3 \%(26 / 63)$ in Kurd, 8.2\% (7/85) in Arab, and 5.9\% (3/51) in Thoroughbred.

By using the agr typing method, all retrieved isolates fell into one of four previously described agr groups, with types III $(n=30 ; 49.2 \%)$ and IV $(n=28 ; 45.9 \%)$ being predominant followed by types II $(n=2,3.3 \%)$ and I $(n=1,1.6 \%)$. Amplification of the polymorphic $\mathrm{X}$ region of the spa gene from the isolates yielded four differently sized amplicons of approximately $1360,1310,1260$, and $1130 \mathrm{bp}$ that were distributed in isolates at $44.3,29.5,16.4$, and $9.8 \%$, respectively. Restriction of the resulting amplicons with HaeII distinguished the isolates into eight genotypic patterns designated as N1-N8 (Fig. 1), of which patterns N2 $(37.7 \% ; n=23)$ and $\mathrm{N} 4(29.5 \% ; n=18)$ were predominant in West and East Azerbaijan provinces, respectively (Table 1). As shown, the greatest diversity was found in isolates obtained from Arab breed with seven isolates assigned to five spa-RFLP patterns. Based on sequencing and determining spa repeat successions, the representative strains of each RFLP pattern (N1-N8) were assigned to spa type t084, t2484, t937, t127, t1383, t11926, t1166, and t12595, respectively. The spa gene sequence of the representative strain of each RFLP pattern (N1-N8) was submitted to the GenBank database and was assigned the following GenBank accession numbers: MF175192 (correspond to t084), MF175204 (t2484), MF175193 (t937), MF175203 (t127), MF175202 (t1383), MF175197 (t11926), MF175198 (t1166), and MF175200 (t12595).

Regarding the BURP analysis, the resulting spa types were clustered into one group (no founder) that consists of spa types t1383 and t127. The spa types t084, t937, t1116, t2484, t11926, and t12595 were not assigned to any BURP group and were identified as singletons (Table 2).

MLST resolved the representative spa types into seven different STs (Table 2). Using the stringent definition of a group, analysis with eBURST showed that the identified STs (with the exception of ST2151 that was shown to be unlinked 'singleton ST') can be divided into four major groups, out of a total of 83 groups dividing all of the currently available STs in the S. aureus MLST. Each of the detected STs associated with their clonal complexes represented by figures drawn by eBURST (Fig. 2).

The phylogenetic analysis of eight representative strains of each RFLP pattern along with five MRSA strains grouped them in two great clusters (I and II) (Fig. 3). The two predominant RFLP types N2 (correspond to ST2151-t2484) and N4 (correspond to ST1-t127) showed lower phylogenetic similarity and were placed in different clusters.

Five of 61 S. aureus isolates (8.2\%) were found to be MRSA, which belonged to clonal types ST2151-t2484-SCCmecIVa $(n=2)$, ST15-t084-SCCmecIVa, ST1-t1383-SCCmecIVa, and ST1278-t12595-SCCmecIVa (one isolate each). Of these, three were isolated from Kurdish horses aged 7-year-old $(n=2)$ and 9-year-old $(n=1)$, one from Crossbred aged 7 years, and one from Persian Arab aged 8 years (Table 1). The spa sequence of a MRSA strains has been deposited in NCBI GenBank under accession numbers MF175194-MF175196, MF175199, and

Table 1 Prevalence and genotypic characteristics of nasal S. aureus isolates from healthy horses on the basis of breed and sampling region

\begin{tabular}{|c|c|c|c|c|c|c|c|c|c|c|c|}
\hline \multirow[t]{2}{*}{ Province } & \multirow[t]{2}{*}{ Breed } & \multirow{2}{*}{$\begin{array}{l}\text { No. of horses } \\
\text { sampled }\end{array}$} & \multirow{2}{*}{$\begin{array}{l}\text { No. of S. aureus-positive } \\
\text { horses [\%] }\end{array}$} & \multicolumn{8}{|c|}{ spa-RFLP pattern (spa-type) } \\
\hline & & & & $\begin{array}{l}\mathrm{N} 1 \\
(\mathrm{t} 084)\end{array}$ & $\begin{array}{l}\mathrm{N} 2 \\
\text { (t2484) }\end{array}$ & $\begin{array}{l}\mathrm{N} 3 \\
\text { (t937) }\end{array}$ & $\begin{array}{l}\mathrm{N} 4 \\
\text { (t127) }\end{array}$ & $\begin{array}{l}\mathrm{N} 5 \\
\text { (t1383) }\end{array}$ & $\begin{array}{l}\text { N6 } \\
\text { (t11926) }\end{array}$ & $\begin{array}{l}\mathrm{N} 7 \\
(\mathrm{t} 1166)\end{array}$ & $\begin{array}{l}\mathrm{N} 8 \\
(\mathrm{t} 12595)\end{array}$ \\
\hline \multicolumn{12}{|c|}{ East Azerbaijan } \\
\hline & Crossbred & 55 & $16[29.1 \%]$ & - & - & - & 12 & $4^{\mathrm{a}}$ & - & - & - \\
\hline & Turkmen & 47 & $9[19.1 \%]$ & - & 3 & - & 6 & - & - & - & - \\
\hline \multicolumn{12}{|c|}{ West Azerbaijan } \\
\hline & Kurd & 63 & $26[41.3 \%]$ & - & $20^{\mathrm{b}}$ & 3 & - & - & - & - & $3^{\mathrm{a}}$ \\
\hline \multicolumn{12}{|l|}{ Yazd } \\
\hline & Persian Arab & 85 & $7[8.2 \%]$ & $2^{\mathrm{a}}$ & - & 2 & - & 1 & 1 & 1 & - \\
\hline & Thoroughbred & 51 & $3[5.9 \%]$ & - & - & - & - & - & - & - & 3 \\
\hline Total & & 301 & $61[20.3 \%]$ & 2 & 23 & 5 & 18 & 5 & 1 & 1 & 6 \\
\hline
\end{tabular}

${ }^{\text {a }}$ One of these isolates was methicillin-resistant $S$. aureus (MRSA)

${ }^{\mathrm{b}}$ Two of these isolates were methicillin-resistant $S$. aureus (MRSA) 
Fig. 1 Restriction polymorphism in the spa variable region of S. aureus nasal isolates recovered from healthy horses. Examples of the different restriction types obtained are shown: type N1 (lane 1), type N2 (lane 2), type N3 (lane 3), type N4 (lane 4), type N5 (lane 5), type N6 (lane 6), type N7 (lane 7), and type N8 (lane 8).

Molecular weight marker (100-bp DNA ladder; Thermo Scientific) is shown in lane $\mathrm{M}$

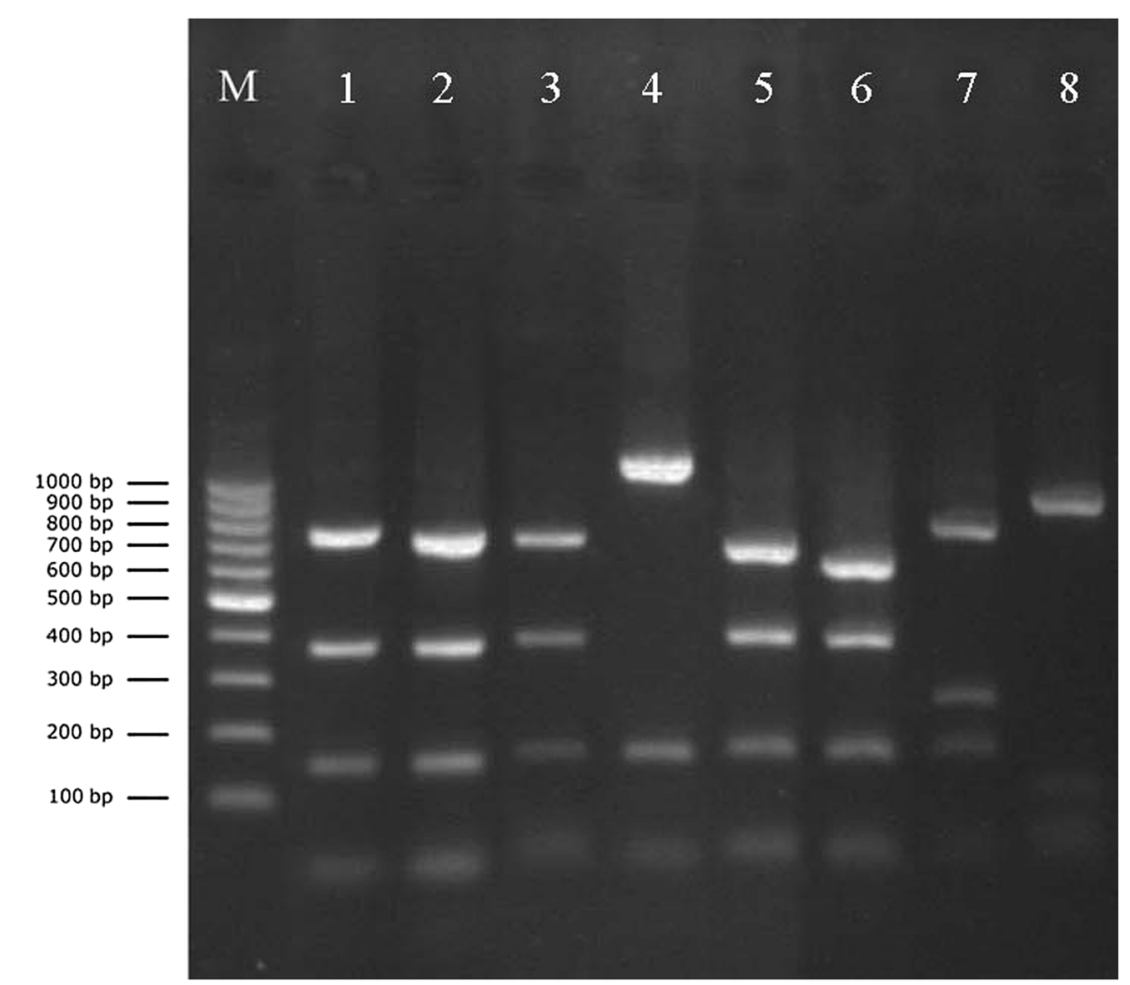

MF175201. Regarding Panton-Valentine leukocidin (PVL), the lukS-lukF-PV genes were not found in any of tested isolates.

Statistical analysis revealed that the rate of $S$. aureus nasal carriage $(P<0.05)$ varies among the studied geographical locations, with the high incidence in West Azerbaijan province $(41.3 \%)$ and the lowest incidence in Yazd province (7.3\%).

\section{Discussion}

The overall isolation rate of $S$. aureus from the nose of healthy horses was found to be $20.3 \%$ (61/301), with a significant difference across the studied regions. This rate is higher than those reported in healthy horses in Denmark (Islam et al. 2017) and Canada (Burton et al. 2008), but lower than the report in Malaysia (Zunita et al. 2008). Differences in environmental factors, equine husbandry practices and host characteristics could account for these discrepancies.

Our findings revealed that Iranian horses can act as a reservoir for diverse clones of methicillin-resistant and -susceptible $S$. aureus, which is consistent with the findings of Islam et al. (2017). However, the observed clonal types in this study were considerably different from that of other countries, with the exception of types ST133-t1166 and ST1-t127

Table 2 Overview of representative spa PCR-RFLP patterns and their corresponding spa types, spa clonal complex (spa-CC), MLST sequence types (MLST_ST), and MLST clonal complexes (MLST_CC)

\begin{tabular}{|c|c|c|c|c|c|}
\hline RFLP pattern & spa type & spa repeat succession & spa-CC & MLST_ST & MLST_CC \\
\hline N1 & $\mathrm{t} 084^{\mathrm{a}}$ & $07-23-12-34-34-12-12-23-02-12-23$ & SGT & 15 & 5 \\
\hline $\mathrm{N} 2$ & $\mathrm{t} 2484^{\mathrm{a}}$ & $04-20-69-31-70-13-17-16-16$ & SGT & 2151 & SGT \\
\hline N3 & t937 & $08-16-34-24-34-34-17-17$ & SGT & 291 & 398 \\
\hline N4 & $\mathrm{t} 127$ & $07-23-21-16-34-33-13$ & Cluster 1 (NF) & 1 & 5 \\
\hline N5 & $\mathrm{t} 1383^{\mathrm{a}}$ & $07-23-21-33-13$ & Cluster 1 (NF) & 1 & 5 \\
\hline N6 & $\mathrm{t} 11926$ & $04-20-69-25-16$ & SGT & 700 & 130 \\
\hline N7 & $\mathrm{t} 1166$ & $03-16-21-17-23-13-17-17-17-23-24$ & SGT & 133 & 133 \\
\hline N8 & $\mathrm{t} 12595^{\mathrm{a}}$ & $04-17-34-17-32-23-24$ & SGT & 1278 & 5 \\
\hline
\end{tabular}

$N F$ no founder, $S G T$ singleton, MLST multilocus sequence typing, ST sequence type

${ }^{\text {a }}$ spa types containing MRSA 


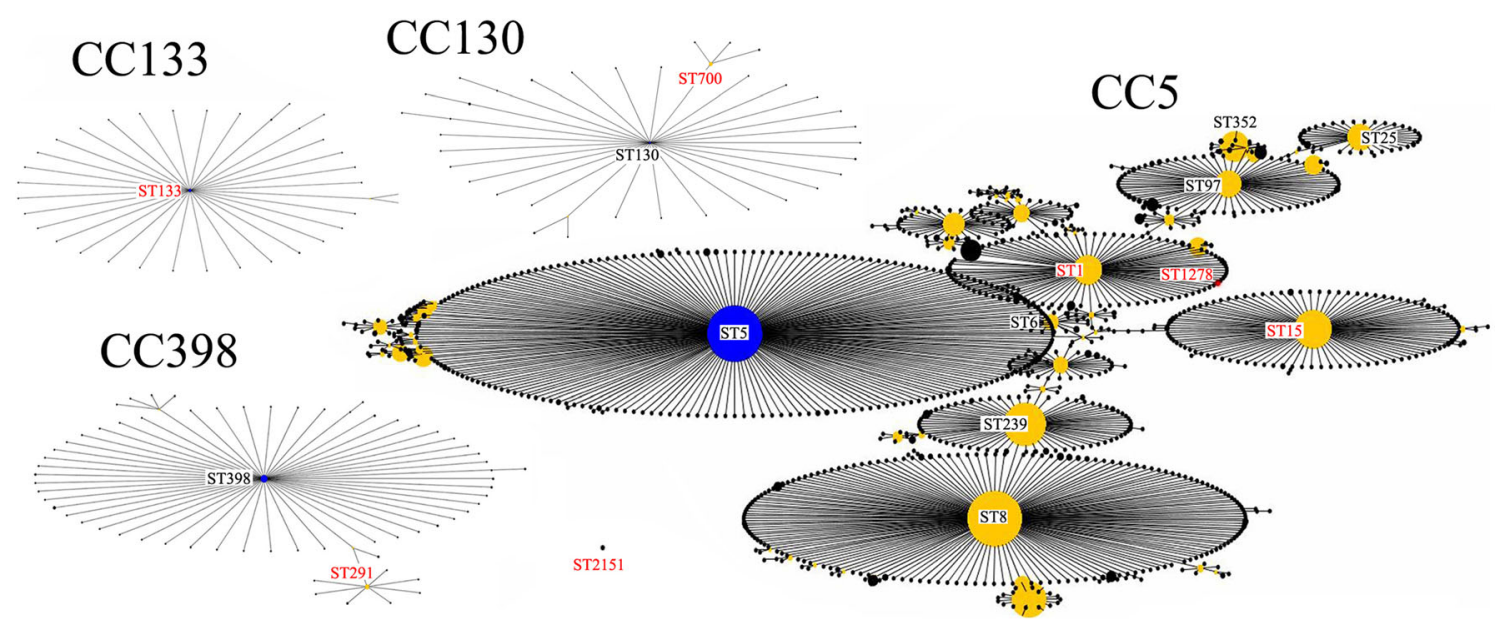

Fig. 2 Population snapshot of $S$. aureus lineages associated with their clonal complexes. All STs identified in this study are highlighted in red, together with their clonal complexes (CC). The primary and subgroup

that have been described in MSSA of horses in Denmark (Islam et al. 2017). The later clonal type has also been isolated from horse MRSA infections in Austria (Cuny et al. 2008; Loncaric et al. 2014). These findings indicate that some specialized clones are world-wide in distribution while the others appear to be limited to a specific geographic area. Further studies are required to better understand the geographical distribution of $S$. aureus clones in different countries. The most common clonal types in East (ST1-t127) and West Azerbaijan (ST2151-t2484) provinces were found not to be closely related, indicating a possible difference in their evolutionary origin. ST1-t127 has been reported from various sources founders of the group are colored blue and yellow, respectively. Each dot represents a single ST, and the size of each dot is proportional to the number of isolates globally deposited

including milk samples (Basanisi et al. 2017), production chain of dairy products (Papadopoulos et al. 2018), seafood and the aquatic environment (Murugadas et al. 2017), small ruminants' meat (Sergelidis et al. 2015), as well as human specimens (Manara et al. 2018), while ST2151-t2484, as far as we know, has only been isolated from donkeys in Tunisia (Gharsa et al. 2012). S. aureus isolates belonging to clonal CC398 have emerged over the previous decade as a risk to livestock workers (Smith and Wardyn 2015). This study detected, for the first time, a double-locus variant (DLV) of the livestock associated S. aureus ST398 (ST291-t937) in five MSSA isolates for which MRSA ST291 has previously been

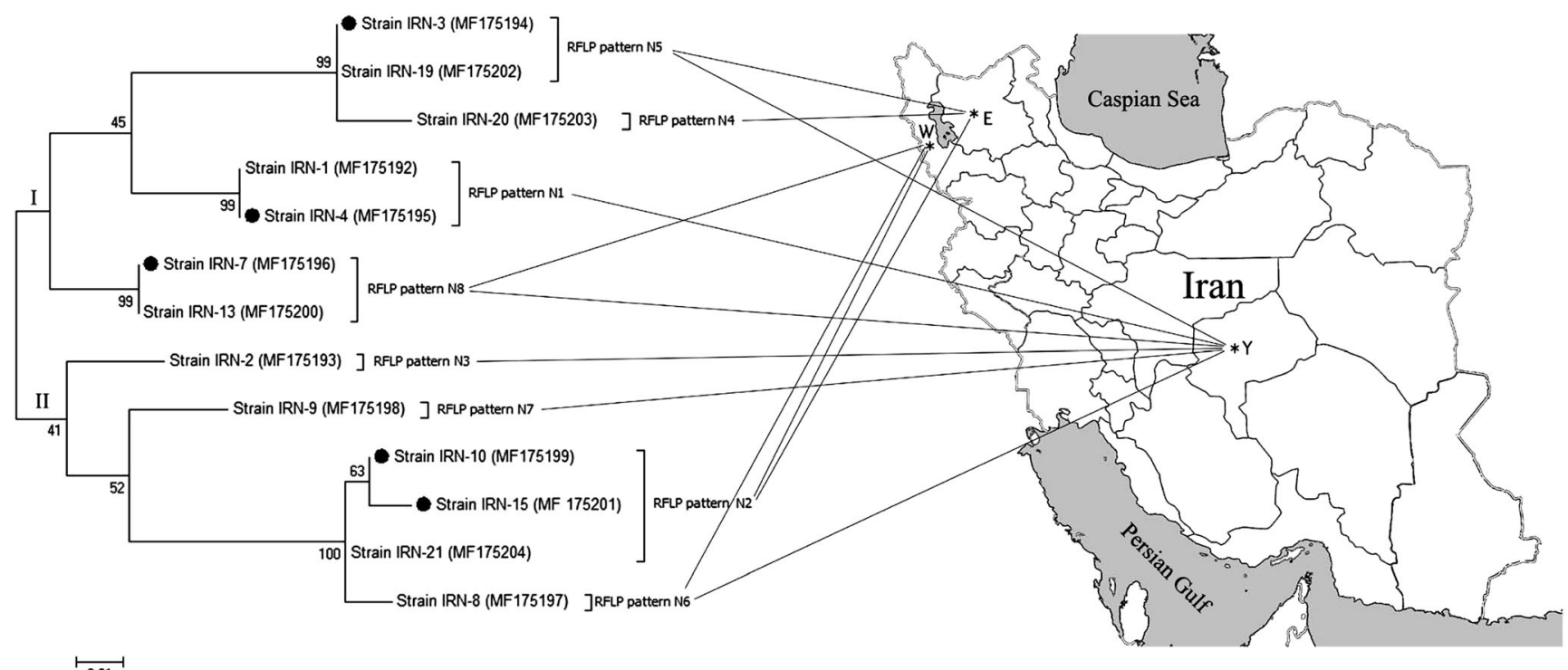

Fig. 3 Phylogenetic tree constructed based on nucleotide sequence of $\mathrm{X}$ region of the spa gene from eight strains of $S$. aureus (representatives of eight patterns obtained by RFLP) along with five MRSA strains isolated from the nares of horses, using the maximum likelihood method with bootstrap of 1000 replicates. Each strain is indicated by the $S$. aureus sample number followed by the GenBank accession number given in parenthesis. The MRSA isolates of the current study are indicated by round $(\bullet)$. E: East Azerbaijan province; W: West Azerbaijan province; Y: Yazd province 
reported from human infections in Iran (Havaei et al. 2013; Ohadian Moghadam et al. 2015). This observation raises concerns about conversions of ST291-MSSA into ST291-MRSA in the community. Additionally, ST291-t937 MSSA has earlier been recognized in the nasal cavity of a dairy cow in Belgium (Vandendriessche et al. 2014) and a healthy human in India (Shambat et al. 2012). These findings indicate that nasal cavity of both humans and animals may constitute a colonization niche for this clone in some parts of the world. The finding of spa type 11926 for the first time in one MSSA horse nasal isolates is unexpected, as this has just been reported from Germany (https://spa.ridom.de/spa-t11926.shtml). Whole-genome sequencing (WGS) will be a useful tool to get insights into its epidemiology and phylogenetic relatedness. Despite the number of $S$. aureus from Persian Arab breed was limited, a wide variety of clonal types were identified. This may be accentuated by the genetic heterogeneity of this breed over time, as Persian Arab is one of the oldest breeds in the world and is distributed throughout the country for centuries and originated from a vast number of mares (Moridi et al. 2013).

The anterior nares are among the most widely studied MRSA colonization sites in animals and in humans (Karkaba et al. 2016). We detected MRSA in 1.7\% (5/301) of the horses in the study population, which is somewhat similar to that reported in western Canada (Tokateloff et al. 2009), however, lower than those reported from horses in Denmark and Australia (Axon et al. 2011; Islam et al. 2017), but higher than the $0.53 \%$ found in horses in Belgium (Van den Eede et al. 2012). MRSA isolates were genoyped as ST15 (spa type t084), ST1 (t1383), ST2151 (t2484; $n=2)$, and ST1278 (t12595), and all of them contained SCCmec type IVa. S. aureus ST15 and ST1 are typical human associated clonal lineages (Cuny et al. 2010), pointing towards a possible human to horse transmission. It is also interesting to point out that the MRSA t084 strains have previously been recovered among isolates from nasal colonization of students (JaponiNejad et al. 2013) and also isolated from healthcare and community-acquired infections in humans in Iran (Fasihi et al. 2017), indicating a worrisome situation with the possibility of its zoonotic potential. As far as we know, the observed ST2151-MRSA in the current study has only been isolated from donkeys in Tunisia (Gharsa et al. 2012), while t12595-MRSA has just been reported from Pakistan (http:// spa.ridom.de/spa-t12595.shtml). MRSA and MSSA isolates from our study were found to be genetically similar, which supports the hypothesis that some MSSA strains may be more receptive to the transfer of a mobile SCCmec element (Katayama et al. 2005). However, this finding is in contrast with the results of the previous study where MRSA and MSSA strains from horses were not clonally related and they presented different spa types (Islam et al. 2017). Three out of five MRSA isolates identified in this study were originated from Kurd breed, but the reasons behind this are unclear. However, stress due to transportation, crossborder dissemination, direct contact with humans and other animals during life in an open environment may be responsible factors for higher prevalence of MRSA carrier in this breed. To what extent these and other nonmodifiable risk factors play a role in MRSA nasal colonization warrants further investigation. The lukS-lukF-PV genes were not found in any of the $S$. aureus isolates tested, which is in agreement with other studies (Tokateloff et al. 2009; Agabou et al. 2017; Islam et al. 2017).

Colonization is a multifactorial process that requires a variety of adaptive mechanisms, including nutrient acquisition, adherence to host tissues, and evasion of, or protection against, host defenses (Kiser et al. 1999). The role of $a g r$ mediated inter-species and intra-strain interferences in nasal colonization has also been proposed (Lina et al. 2003; Barbagelata et al. 2011). In this study, isolates belonging to different clonal types often gave the agr types III $(n=30$; $49.2 \%)$ and IV ( $n=27 ; 44.3 \%)$, suggesting well adaptation of subset of $S$. aureus isolates to the nose of horses likely by agr regulatory system. More expanded study is, however, required to investigate this hypothesis.

In summary, this study, for the first time, revealed that Iranian horse population can be healthy carriers of diverse clones of $S$. aureus (either MSSA or MRSA). The results also provide evidence for the presence of human-related MRSA clones, emphasizing the importance of comprehensive epidemiological surveillance. In addition, the rate of $S$. aureus nasal carriage varied with geographic locations. Further studies are needed to determine the epidemiology and risk factors, such as cross-contamination via the environment and its reservoirs, for $S$. aureus nasal colonization of horses in Iran.

Acknowledgments The authors are very grateful to Professor Alexander Mellmann from University of Münster, Institute of Hygiene, Germany, for conducting the BURP analysis. We are also thankful to Dr. M. Morovati, Dr. G. Jalilzadeh and Dr. S. Rostami for their help in sample collection, and Mrs. Mitra Panahi and Dr. S. Hosseinzadeh for technical assistance.

Funding information The Research Deputy of Urmia University financially supported the current investigation.

\section{Compliance with ethical standards}

The study protocol was approved by the Urmia University Animal Ethics Committee (ethical clearance number 1241).

Conflict of interest The authors declare that they have no conflict of interest.

Research involving human participants and/or animals Not applicable. 
Informed consent The authors confirm that this article's content has no animal or human participants in research.

\section{References}

Agabou A, Ouchenane Z, Ngba Essebe C, Khemissi S, Chehboub MTE, Chehboub IB, Sotto A, Dunyach-Remy C, Lavigne JP (2017) Emergence of nasal carriage of ST80 and ST152 PVL+ Staphylococcus aureus isolates from livestock in Algeria. Toxins 9

AL-Tam F, Brunel AS, Bouzinbi N, Corne P, Banuls AL, Shahbazkia HR (2012) DNAGear-a free software for spa type identification in Staphylococcus aureus. BMC Res Notes 5:642

Asghar AH (2014) Molecular characterization of methicillin-resistant Staphylococcus aureus isolated from tertiary care hospitals. Pak J Med Sci 30:698-702

Axon J, Carrick J, Barton M, Collins N, Russell C, Kiehne J, Coombs G (2011) Methicillin-resistant Staphylococcus aureus in a population of horses in Australia. Aust Vet J 89:221-225

Barbagelata MS, Alvarez L, Gordiola M, Tuchscherr L, von Eiff C, Becker K, Sordelli D, Buzzola F (2011) Auxotrophic mutant of Staphylococcus aureus interferes with nasal colonization by the wild type. Microbes Infect 13:1081-1090

Basanisi MG, La Bella G, Nobili G, Franconieri I, La Salandra G (2017) Genotyping of methicillin-resistant Staphylococcus aureus (MRSA) isolated from milk and dairy products in South Italy. Food Microbiol 62:141-146

Boye K, Bartels MD, Andersen IS, Moller JA, Westh H (2007) A new multiplex PCR for easy screening of methicillin-resistant Staphylococcus aureus SCCmec types I-V. Clin Microbiol Infect 13:725-727

Brakstad OG, Aasbakk K, Maeland JA (1992) Detection of Staphylococcus aureus by polymerase chain reaction amplification of the nuc gene. J Clin Microbiol 30:1654-1660

Burton S, Reid-Smith R, McClure JT, Weese JS (2008) Staphylococcus aureus colonization in healthy horses in Atlantic Canada. Can Vet $\mathrm{J}$ 49:797-799

Carfora V, Caprioli A, Grossi I, Pepe M, Alba P, Lorenzetti S, Amoruso R, Sorbara L, Franco A, Battisti A (2016) A methicillin-resistant Staphylococcus aureus (MRSA) sequence type 8, spa type 111469 causing infection and colonizing horses in Italy. Pathog Dis 74: $\mathrm{ftw} 025$

CLSI (2009) Performance standards for antimicrobial Susceptability testing. Clinical and laboratory standards institute. Wayne, PA

Cohn LA, Middleton JR (2010) A veterinary perspective on methicillinresistant staphylococci. J Vet Emerg Crit Care 20:31-45

Cuny C, Strommenger B, Witte W, Stanek C (2008) Clusters of infections in horses with MRSA ST1, ST254, and ST398 in a veterinary hospital. Microb Drug Resist 14:307-310

Cuny C, Friedrich A, Kozytska S, Layer F, Nubel U, Ohlsen K, Strommenger B, Walther B, Wieler L, Witte W (2010) Emergence of methicillin-resistant Staphylococcus aureus (MRSA) in different animal species. Int J Med Microbiol 300:109-117

Enright MC, Day NP, Davies CE, Peacock SJ, Spratt BG (2000) Multilocus sequence typing for characterization of methicillinresistant and methicillin-susceptible clones of Staphylococcus aureus. J Clin Microbiol 38:1008-1015

Fasihi Y, Kiaei S, Kalantar-Neyestanaki D (2017) Characterization of SCCmec and spa types of methicillin-resistant Staphylococcus aureus isolates from health-care and community-acquired infections in Kerman, Iran. J Epidemiol Glob Health 7:263-267

Gharsa H, Ben Sallem R, Ben Slama K, Gomez-Sanz E, Lozano C, Jouini A, Klibi N, Zarazaga M, Boudabous A, Torres C (2012) High diversity of genetic lineages and virulence genes in nasal Staphylococcus aureus isolates from donkeys destined to food consumption in Tunisia with predominance of the ruminant associated $\mathrm{CC} 133$ lineage. BMC Vet Res 8:203

Gilot P, Lina G, Cochard T, Poutrel B (2002) Analysis of the genetic variability of genes encoding the RNA III-activating components Agr and TRAP in a population of Staphylococcus aureus strains isolated from cows with mastitis. J Clin Microbiol 40:4060-4067

Gopal S, Divya KC (2017) Can methicillin-resistant Staphylococcus aureus prevalence from dairy cows in India act as potential risk for community-associated infections?: a review. Vet World 10:311-318

Harmsen D, Claus H, Witte W, Rothganger J, Claus H, Turnwald D, Vogel U (2003) Typing of methicillin-resistant Staphylococcus aureus in a university hospital setting by using novel software for spa repeat determination and database management. J Clin Microbiol 41:5442-5448

Havaei SA, Azimian A, Fazeli H, Naderi M, Ghazvini K, Samiee SM, Soleimani M (2013) Isolation of Asian endemic and livestock associated clones of methicillin resistant Staphylococcus aureus from ocular samples in northeastern Iran. Iran J Microbiol 5:227-232

Islam MZ, Espinosa-Gongora C, Damborg P, Sieber RN, Munk R, Husted L, Moodley A, Skov R, Larsen J, Guardabassi L (2017) Horses in Denmark are a reservoir of diverse clones of methicillin-resistant and -susceptible Staphylococcus aureus. Front Microbiol 8:543

Japoni-Nejad A, Rezazadeh M, Kazemian H, Fardmousavi N, van Belkum A, Ghaznavi-Rad E (2013) Molecular characterization of the first community-acquired methicillin-resistant Staphylococcus aureus strains from Central Iran. Int J Infect Dis 17:e949-e954

Johler S, Layer F, Stephan R (2011) Comparison of virulence and antibiotic resistance genes of food poisoning outbreak isolates of Staphylococcus aureus with isolates obtained from bovine mastitis milk and pig carcasses. J Food Prot 74:1852-1859

Karkaba A, Benschop J, Hill KE, Grinberg A (2016) Characterisation of methicillin-resistant Staphylococcus aureus clinical isolates from animals in New Zealand, 2012-2013, and subclinical colonisation in dogs and cats in Auckland. N Z Vet J:1-6

Katayama Y, Robinson DA, Enright MC, Chambers HF (2005) Genetic background affects stability of mecA in Staphylococcus aureus. J Clin Microbiol 43:2380-2383

Kiser KB, Cantey-Kiser JM, Lee JC (1999) Development and characterization of a Staphylococcus aureus nasal colonization model in mice. Infect Immun 67:5001-5006

Koreen L, Ramaswamy SV, Graviss EA, Naidich S, Musser JM, Kreiswirth BN (2004) spa typing method for discriminating among Staphylococcus aureus isolates: implications for use of a single marker to detect genetic micro- and macrovariation. J Clin Microbiol 42:792-799

Lakhundi S, Zhang K (2018) Methicillin-resistant Staphylococcus aureus: molecular characterization, evolution, and epidemiology. Clin Microbiol Rev 31:e00020-e0018

Lina G, Piemont Y, Godail-Gamot F, Bes M, Peter MO, Gauduchon V, Vandenesch F, Etienne J (1999) Involvement of Panton-valentine leukocidin-producing Staphylococcus aureus in primary skin infections and pneumonia. Clin Infect Dis 29:1128-1132

Lina G, Boutite F, Tristan A, Bes M, Etienne J, Vandenesch F (2003) Bacterial competition for human nasal cavity colonization: role of staphylococcal agr alleles. Appl Environ Microbiol 69:18-23

Liu J, Chen D, Peters BM, Li L, Li B, Xu Z, Shirliff ME (2016) Staphylococcal chromosomal cassettes mec (SCCmec): a mobile genetic element in methicillin-resistant Staphylococcus aureus. Microb Pathog 101:56-67

Loncaric I, Kunzel F, Licka T, Simhofer H, Spergser J, Rosengarten R (2014) Identification and characterization of methicillin-resistant Staphylococcus aureus (MRSA) from Austrian companion animals and horses. Vet Microbiol 168:381-387

Maddox TW, Clegg PD, Diggle PJ, Wedley AL, Dawson S, Pinchbeck GL, Williams NJ (2011) Cross-sectional study of antimicrobialresistant bacteria in horses. Part 1: prevalence of antimicrobial- 
resistant Escherichia coli and methicillin-resistant Staphylococcus aureus. Equine Vet J 44:289-296

Manara S, Pasolli E, Dolce D, Ravenni N, Campana S, Armanini F, Asnicar F, Mengoni A, Galli L, Montagnani C, Venturini E, RotaStabelli O, Grandi G, Taccetti G, Segata N (2018) Whole-genome epidemiology, characterisation, and phylogenetic reconstruction of Staphylococcus aureus strains in a paediatric hospital. Genome Med 10:82

Mellmann A, Weniger T, Berssenbrugge C, Rothganger J, Sammeth M, Stoye J, Harmsen D (2007) Based upon repeat pattern (BURP): an algorithm to characterize the long-term evolution of Staphylococcus aureus populations based on spa polymorphisms. BMC Microbiol 7:98

Milheirico C, Oliveira DC, de Lencastre H (2007) Multiplex PCR strategy for subtyping the staphylococcal cassette chromosome mec type IV in methicillin-resistant Staphylococcus aureus: SCCmec IV multiplex. J Antimicrob Chemother 60 (1):42-48

Moridi M, Masoudi AA, Vaez Torshizi R, Hill EW (2013) Mitochondrial DNA D-loop sequence variation in maternal lineages of Iranian native horses. Anim Genet 44:209-213

Murakami K, Minamide W, Wada K, Nakamura E, Teraoka H, Watanabe S (1991) Identification of methicillin-resistant strains of staphylococci by polymerase chain reaction. J Clin Microbiol 29:2240-2244

Murugadas V, Toms CJ, Reethu SA, Lalitha KV (2017) Multilocus sequence typing and staphylococcal protein a typing revealed novel and diverse clones of methicillin-resistant Staphylococcus aureus in seafood and the aquatic environment. J Food Prot 80:476-481

Ohadian Moghadam S, Pourmand MR, Mahmoudi M, Sadighian H (2015) Molecular characterization of methicillin-resistant Staphylococcus aureus: characterization of major clones and emergence of epidemic clones of sequence type (ST) 36 and ST 121 in Tehran, Iran. FEMS Microbiol Lett 362:fnv043

O'Hara FP, Suaya JA, Ray GT, Baxter R, Brown ML, Mera RM, Close NM, Thomas E, Amrine-Madsen H (2016) Spa typing and multilocus sequence typing show comparable performance in a macroepidemiologic study of Staphylococcus aureus in the United States. Microb Drug Resist 22:88-96

Papadopoulos P, Papadopoulos T, Angelidis AS, Boukouvala E, Zdragas A, Papa A, Hadjichristodoulou C, Sergelidis D (2018) Prevalence of Staphylococcus aureus and of methicillin-resistant S. aureus (MRSA) along the production chain of dairy products in NorthWestern Greece. Food Microbiol 69:43-50

Peterson AE, Davis MF, Awantang G, Limbago B, Fosheim GE, Silbergeld EK (2012) Correlation between animal nasal carriage and environmental methicillin-resistant Staphylococcus aureus isolates at U.S. horse and cattle farms. Vet Microbiol 160:539-543

Sergelidis D, Papadopoulos T, Komodromos D, Sergelidou E, Lazou T, Papagianni M, Zdragas A, Papa A (2015) Isolation of methicillin- resistant Staphylococcus aureus from small ruminants and their meat at slaughter and retail level in Greece. Lett Appl Microbiol 61:498-503

Shambat S, Nadig S, Prabhakara S, Bes M, Etienne J, Arakere G (2012) Clonal complexes and virulence factors of Staphylococcus aureus from several cities in India. BMC Microbiol 12:64

Smith TC, Wardyn SE (2015) Human infections with Staphylococcus aureus CC398. Curr Environ Health Rep 2:41-51

Tokateloff N, Manning ST, Weese JS, Campbell J, Rothenburger J, Stephen C, Bastura V, Gow SP, Reid-Smith R (2009) Prevalence of methicillin-resistant Staphylococcus aureus colonization in horses in Saskatchewan, Alberta, and British Columbia. Can Vet J 50: $1177-1180$

Van den Eede A, Martens A, Feryn I, Vanderhaeghen W, Lipinska U, Gasthuys F, Butaye P, Haesebrouck F, Hermans K (2012) Low MRSA prevalence in horses at farm level. BMC Vet Res 8:213

Vandendriessche S, Vanderhaeghen W, Larsen J, de Mendonca R, Hallin M, Butaye P, Hermans K, Haesebrouck F, Denis O (2014) High genetic diversity of methicillin-susceptible Staphylococcus aureus (MSSA) from humans and animals on livestock farms and presence of SCCmec remnant DNA in MSSA CC398. J Antimicrob Chemother 69:355-362

Weese JS, van Duijkeren E (2010) Methicillin-resistant Staphylococcus aureus and Staphylococcus pseudintermedius in veterinary medicine. Vet Microbiol 140:418-429

Weese JS, Archambault M, Willey BM, Hearn P, Kreiswirth BN, SaidSalim B, McGeer A, Likhoshvay Y, Prescott JF, Low DE (2005) Methicillin-resistant Staphylococcus aureus in horses and horse personnel, 2000-2002. Emerg Infect Dis 11:430-435

Weese JS, Caldwell F, Willey BM, Kreiswirth BN, McGeer A, Rousseau J, Low DE (2006) An outbreak of methicillin-resistant Staphylococcus aureus skin infections resulting from horse to human transmission in a veterinary hospital. Vet Microbiol 114:160-164

Wichelhaus TA, Hunfeld KP, Boddinghaus B, Kraiczy P, Schafer V, Brade V (2001) Rapid molecular typing of methicillin-resistant Staphylococcus aureus by PCR-RFLP. Infect Control Hosp Epidemiol 22:294-298

Zunita Z, Bashir A, Hafizal A (2008) Occurrence of multidrug resistant Staphylococcus aureus in horses in Malaysia. Vet World 1:165-167

Publisher's note Springer Nature remains neutral with regard to jurisdictional claims in published maps and institutional affiliations. 